\title{
Spatio-Temporal Grassland Development in Inner Mongolia after Implementation of the First Comprehensive Nation-Wide Grassland Conservation Program
}

\author{
Zhichao Xue *, Martin Kappas (D) and Daniel Wyss \\ Cartography, GIS and Remote Sensing Department, Institute of Geography, University of Göttingen, \\ 37077 Göttingen, Germany; mkappas@gwdg.de (M.K.); daniel.wyss@uni-goettingen.de (D.W.) \\ * Correspondence: zhichao.xue@geo.uni-goettingen.de; Tel.: +49-551-39-8051
}

check for

updates

Citation: Xue, Z.; Kappas, M.;

Wyss, D. Spatio-Temporal Grassland Development in Inner Mongolia after Implementation of the First Comprehensive Nation-Wide Grassland Conservation Program. Land 2021, 10, 38. https://doi.org/ 10.3390/land10010038

Received: 25 November 2020 Accepted: 31 December 2020 Published: 5 January 2021

Publisher's Note: MDPI stays neutral with regard to jurisdictional clai$\mathrm{ms}$ in published maps and institutional affiliations.

Copyright: (C) 2021 by the authors. Licensee MDPI, Basel, Switzerland. This article is an open access article distributed under the terms and conditions of the Creative Commons Attribution (CC BY) license (https:// creativecommons.org/licenses/by/ $4.0 /)$.

\begin{abstract}
Protection of the grassland's ecological environment and improvement of people's livelihoods are major tasks for the management of pastoral areas in Inner Mongolia. The comprehensive program for grassland conservation in China, the Subsidy and Incentive System for Grassland Conservation (SISGC), was launched in 2011. To comprehend the effects of this major step towards sustainable grassland development, this study focuses on the spatio-temporal development of grasslands in Inner Mongolia since 2011. Through the combination of MODIS (Moderate-resolution Imaging Spectroradiometer) satellite data with up to date meteorological data, we used the indicators of Fractional Vegetation Cover (FVC) and Net Primary Productivity (NPP) to analyze qualitative and quantitative grassland changes. A classification system on the pixel level, reflecting change trends and fluctuations of both FVC and NPP, was applied to monitor and analyze the grassland development from 2011 to 2019. In particular, the spatial transfer matrix of the recent two years (2018 to 2019) was analyzed to reveal the latest potential issues and random impact factors. The results show a positive overall but spatially unbalanced effect of SISGC, with a prominent positive impact in the semi-desert grassland area. The potential threats from both social and natural aspects as well as the importance of a forecast system for local stakeholders in the pastoral area are discussed.
\end{abstract}

Keywords: Inner Mongolia; grassland cover change; the subsidy and incentive system for grassland conservation; pastoral area

\section{Introduction}

The development of the grassland ecosystem, one of the most vulnerable ecosystems, has aroused a critical worldwide concern in recent decades [1-3], especially under the gradually consistent perception of global climate change. Grassland in the Inner Mongolia Autonomous Region (IMAR) of China belongs to the Eurasian grassland habitat [4] and shows the second highest diversity of indigenous plants in the world [5]. Towards the beginning of the 21st century, IMAR suffered great grassland degradation [6,7]. Protecting the grassland's ecological environment and improving people's livelihoods are major governmental tasks. Recently, it also became an essential requirement for the Beautiful China Construction (BCC) initiative, which was initiatively planned by the 18th Chinese National Congress in 2015. BCC is the blueprint for ecological civilization (a construction goal for Chinese government to emphasize harmony between humans and nature $[8,9]$ ), of fundamental importance for the sustainable development of the Chinese nation and a Chinese practice of the $2030 \mathrm{UN}$ sustainable development agenda.

International grassland conservation and protection trials continuously contribute towards valuable experiences and knowledge of grassland ecosystems on a global scale. An example is the Conservation Reserve Program (CRP), developed by the US federal government. Through rental payment and voluntary participation, the CRP proved to be beneficial for the conservation of grassland, control of soil erosion and even wildlife 
habitat conservation [10]. The Chinese Government has also implemented a series of grassland conservation projects since $2000[11,12]$. These projects are moving from macro-level planning towards local condition adaptation. The Beijing-Tianjin sandstorm source control project launched in 2000, targeted areas mainly located in the sandy and severely degraded dry grassland areas. Key measures included fencing, reseeding and the establishment of grazing bans. In 2003, the Returning Grazing Land to Grassland project was implemented which also focused on severely degraded grassland areas. Seasonal, semi-annual or year-round grazing suspension is implemented regionally. Since 2011, the Subsidy and Incentive System for Grassland Conservation (SISGC) was launched. This is the first all herder inclusive program for grassland conservation in China. Previous projects mainly focused on the degraded regions and provided a subsidy for those who sacrificed their benefits for local grassland conservation. The SISGC would also reward herders who maintain the balance of grassland carrying capacity and livestock, even in a good and undegraded grassland region. Herders switch from passively accepting the implementation of grassland ecological measures to actively carrying out grass-livestock balance and grazing prohibitions followed by corresponding rewards. This positive feedback chain would further enhance the cognition and consciousness of herdsmen and reduce the threat caused by overuse of grasslands under good precipitation conditions.

The first round of SISGC was from 2011 to 2015 and consisted of four regulations. (1) For grasslands that are seriously degraded and not suitable for grazing, a grazing ban is implemented. Central government grants a subsidy to herders of 14.44 USD/ha (1 USD = 6.2284 CNY, in 2015). (2) A grass-livestock balancing reward: for other available grasslands which show a reasonable carrying capacity, and checked by local institutions, the central government will reward the herders who have not overloaded grazing with the standard 3.61 USD/ha. (3) Herders' productivity subsidy: the subsidies for the improvement of livestock variety and herders' production. This subsidy includes 80.28 USD per household for about 2 million herdsmen in eight provinces and autonomous regions. (4) A performance appraisal regulation to improve verification mechanisms. The second round of SISGC started in 2016. The reward and subsidy standard should be adjusted each round by central government, and the specific regions and local accordance subsidy need to be adjusted every year by local government according to the changing condition of grassland. Continuous observation and real-time monitoring of grassland change and pixel-specific analysis are important for an optimal implementation of policy and to balance the interests of relevant stakeholders.

To identify the spatio-temporal grassland cover change, the traditional and effective method is based on in situ surveys, which can provide creditable and precise results but, considering the wide expanses of grassland, this also goes along with costly and timeconsuming intensive fieldwork, limited sites and lagging data processing [13]. With the improvement of spatio-temporal resolution of remote sensing (RS) and data processing technologies, mapping and monitoring of grassland cover change becomes more efficient and is often combined with in situ data for validation [14]. Many researches implement vegetation indexes (VIs) extracted from spectral sensors for grassland monitoring, including normalized difference vegetation index (NDVI) [15], enhanced vegetation index (EVI) [16], net primary productivity (NPP) and surface vegetation coverage [17], etc. There are also synthetic researches based on the analysis of multiple VIs addressing the importance of multiple perspectives [18] through analysis of variations in species composition, grassland desertification and above ground biomass of grassland degradation in semiarid grasslands. Although the VIs are abundant and flexible, and the information on grassland degradation and condition classification show large differences [19], grassland monitoring activities on a regional and global level are gradually providing more specific information to support sustainable grassland management.

In recent decades, many studies have concentrated on the monitoring of vegetation dynamics in IMAR. Some results indicate that vegetation growth has been poor since the beginning of the 21st century and that vegetation cover is lower in comparison to the 
1980s or 1990s [20]. Other contradictory results have shown an increase of vegetation cover or productivity since the year 2000, possibly due to governmental decisions in the field of grassland management and conservation [21,22]. Historic change is always under debate. Considering that SISGC is an annual-based adjustment project, the grassland development analysis during the implementation period seems more practical for local stakeholders. In this research, we attempt to use open access RS data to monitor changes in grassland coverage at pixel level, combining Fractional Vegetation Cover (FVC) and NPP to qualitatively and quantitatively explore the annual grassland change in IMAR. The main objectives of this research are to understand grassland development and its trend since SISGC implementation in 2011. The results can help to support sustainable grassland management strategies for local governments when adjusting to SISGC on an annual basis and provide management references for other global grassland areas.

\section{Materials and Methods}

\subsection{Study Area}

The IMAR, located at $37^{\circ} 24^{\prime} \mathrm{N}$ to $53^{\circ} 23^{\prime} \mathrm{N}$ and $97^{\circ} 12^{\prime} \mathrm{E}$ to $126^{\circ} 04^{\prime} \mathrm{E}$ (Figure 1), is dominated by a temperate continental monsoon climate. The annual precipitation is in the range of $100 \mathrm{~mm}$ to $500 \mathrm{~mm}$, with a majority of precipitation occurring during the growing season between July and September. The mean annual temperature ranges from $-2{ }^{\circ} \mathrm{C}$ to $6{ }^{\circ} \mathrm{C}$. The frost-free period is 70 to 160 days [23]. Grasslands are the main land cover type in IMAR (21.7\% of total China's natural grassland) [24]. Soil types in the region consist of chernozem, chestnut, and calcic brown. Meadow steppe, typical steppe, and desert steppe [25] are spread from east to west, and the production of grassland also gradually decreases accordingly. The average yield of various pastures is $2863.57 \mathrm{~kg} / \mathrm{ha}$ to $344.83 \mathrm{~kg} / \mathrm{ha}$, and the animal carrying capacity is between 104.95 ha and 1589.21 ha per sheep unit [26]. The main grassland types include Stipa krylovii, Leymus chinensis and Artemisia spp. [27].

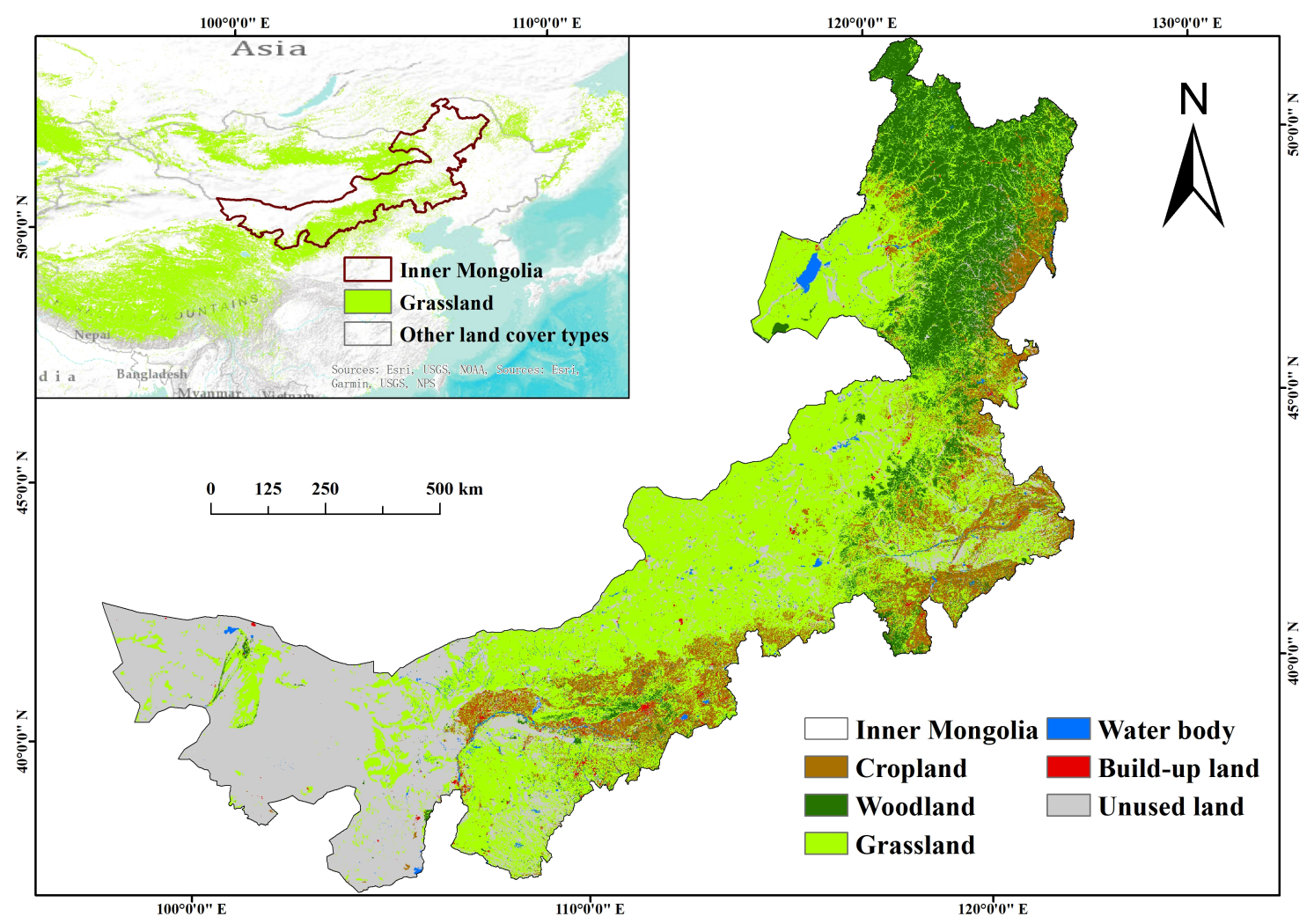

Figure 1. Land cover of Inner Mongolia (Data source: World grassland type: The CCI-LC (Climate Change Initiative, Land Cover) global Land cover map of 2010, ESA, 300 m, type 130; China's land use land cover [28]). 
Animal husbandry is the basic industry of IMAR and occupies a key position in the country. The output of lamb, milk, cashmere and the production capacity of grassland animal husbandry of IMAR are all ranked first in China [26]. Grasslands are closely related to the production, life and cultural development of herders. Over 90\% of herdsmen's income comes from grasslands [26]. In 2019, the per capita disposable income of permanent residents in rural pastoral areas was 2454 USD, about half of the per capita disposable income of all residents in IMAR (4906 USD) [29].

\subsection{Data Sources}

Vegetation index production, meteorological data and the grassland conservation and protection policy in IMAR are basic data sets in this research (Table 1). NDVI and NPP were obtained from moderate-resolution imaging spectroradiometer (MODIS). IMAR is covered by seven tiles of global MODIS data. We collected 1392 tiles of MOD13A1 NDVI data in a temporal resolution of 16 days and spatial resolution of $500 \mathrm{~m}$, and 63 annual MOD17A3HGF NPP data products with $500 \mathrm{~m}$ resolution [30] covering the period from 2011 to 2019. MOD13A1 NDVI data provides VIs, including NDVI and EVI. The algorithm for this product chooses the best available pixel value from the 16-day image composites. The criteria are low cloud cover, a low view angle, and the highest NDVI value. Annual NPP (MOD17A3HGF NPP) is derived from Net Photosynthesis (PSN), which is the difference of the Gross Primary Productivity (GPP) and the Maintenance Respiration (MR).

Table 1. Data sources and brief information.

\begin{tabular}{|c|c|c|c|c|}
\hline Data Indicator & $\begin{array}{c}\text { Spatial } \\
\text { Resolution }\end{array}$ & $\begin{array}{c}\text { Temporal } \\
\text { Resolution }\end{array}$ & Sources & Objective Output \\
\hline NDVI & $500 \mathrm{~m}$ & 16-days & \multirow{2}{*}{ LP DAAC (https:/ /lpdaac.usgs.gov/) } & FVC \\
\hline $\mathrm{NPP}$ & $500 \mathrm{~m}$ & 1 year & & NPP, HNPP, PNPP \\
\hline $\begin{array}{l}\text { Annual mean } \\
\text { temperature }\end{array}$ & 0.5 degree & 1 day & \multirow{2}{*}{$\begin{array}{l}\text { CPC Global Temperature and Precipitation } \\
\text { dataset provided by the NOAA/OAR/ESRL PSL, } \\
\text { Boulder, Colorado, USA (https://psl.noaa.gov/) }\end{array}$} & PNPP \\
\hline $\begin{array}{l}\text { Annual mean } \\
\text { precipitation }\end{array}$ & 0.5 degree & 1 day & & PNPP \\
\hline $\begin{array}{l}\text { Grassland } \\
\text { management }\end{array}$ & - & - & Government website (http:/ / www.nmg.gov.cn/) & $\begin{array}{l}\text { SISGC and policy } \\
\text { context }\end{array}$ \\
\hline
\end{tabular}

Note: NDVI: Normalized Difference Vegetation Index; NPP: Net Primary Productivity; FVC: Fractional Vegetation Cover; HNPP: Human-induced NPP; PNPP: Potential NPP; SISGC: the Subsidy and Incentive System for Grassland Conservation; LP DAAC: the Land Processing Distributed Active Archive Center; CPC: Climate Prediction Center; NOAA: the National Oceanic and Atmospheric Administration; OAR: Oceanic and Atmospheric Research; ESRL: Earth System Research Laboratories; PSL: Physical Sciences Laboratory.

We conducted data preprocessing including data format transformation, reprojection, mosaicking and resampling with the MODIS Reprojection Tool (MRT). To further reduce the influence of clouds, atmosphere and solar altitude angle, we transferred the 16-day NDVI composites to yearly composites using Maximum Value Compositions (MVC), extracted by the Inner Mongolia administrative boundary and thus obtained yearly NDVI products of IMAR from 2011 to 2019.

The Climate Prediction Center (CPC) Global Temperature and Precipitation meteorological dataset from 2011 to 2019 (Table 1), included global daily precipitation and daily maximum and minimum temperatures in a 0.50-degree spatial resolution. We transformed the NetCDF (network Common Data Format) daily value data from 2011 to 2019 into raster sets through raster calculation, projection and resampling. The resulting annual average precipitation and temperature products in a resolution of $500 \mathrm{~m}$ were finally used in conjunction with the processed NPP and NDVI data. 


\subsection{Methods}

There are two key lines for grassland development analysis in this study. One is the indicator of FVC from a qualitative aspect, another is the indicator of NPP from a quantitative aspect. To reveal more information on impact factors for grassland productivity, we developed Human-induced NPP (HNPP) and Potential NPP (PNPP), which will be explained in more detail in Section 2.3.2. Focusing on these four indicators, we analyzed their trends and fluctuations based on a time series change analysis conducted from 2011 until 2019 and between 2018 and 2019. The results are finally discussed and put in context to local sustainable grassland management strategies, SISGC and impacts of climate change and human activities.

\subsubsection{Fractional Vegetation Cover}

FVC is the projected area of vegetation per unit of ground area and an important ecological parameter to evaluate grassland change and degradation [31]. It is assumed that the NDVI value of each pixel is composed of two parts, vegetation NDVI $\left(\mathrm{NDVI}_{\mathrm{V}}\right)$ and soil NDVI (NDVI ${ }_{S}$ ) (see Formula (1)). The linear mixture model [32] is used to estimate FVC. The model has been widely used and has shown to be efficient for global [33], national [17] and regional (IMAR) applications [34]. For instance, Tong et al. used the dimidiate pixel model to analysis FVC change from 1982 to 2010 in IMAR. The results have explained well the correlation with precipitation and the complex impact of human activities [20]. Furthermore, research based on unmanned aerial vehicle imagery in desert steppe of Alxa in the western part of IMAR, proved that the linear mixture model can obtain an accuracy of $83.1 \%$ [35]. In this model, NDVI is not a fixed value due to the influence of atmospheric conditions, humidity and sunlight. The different composition, spatial distribution and seasonal changes in vegetation growth also lead to a spatio-temporal variation of $\mathrm{NDVI}_{\mathrm{v}}$. Due to the lack of large-area measured data, a confidence interval of the NDVI statistical histogram is usually used to obtain the maximum and minimum values and determine the vegetation index of the whole vegetation coverage as well as the bare area [36]. In this study, the cumulative percentages of $5 \%$ and $95 \%$ were selected as confidence intervals, which are widely used in northern China [20,37]. The cumulative percentage of less than $5 \%$ is the approximate pure soil cover vegetation index $\left(\mathrm{NDVI}_{\mathrm{s}}\right)$, and the grassland area with a cumulative percentage greater than $95 \%$ is the pure vegetation cover vegetation index $\left(\mathrm{NDVI}_{\mathrm{V}}\right)$. FVC were calculated annually from 2011 to 2019.

$$
\mathrm{NDVI}=\mathrm{NDVI}_{\mathrm{V}} \times \mathrm{FVC}+\mathrm{NDVI}_{\mathrm{s}} \times(1-\mathrm{FVC}),
$$

\subsubsection{PNPP and HNPP}

PNPP symbolizes potential vegetation conditions under the hypothesis that NPP is affected by climate change only. The Miami model [38] is empirical, derived through correlated mean annual temperature and precipitation values in conjunction with NPP and widely used for analyzing global productivity patterns. The model also acts as a baseline for comparisons [17]. The employed Miami model was used to simulate PNPP. The basic principles of the Miami Model are described by Formulas (2) and (3).

$$
\mathrm{NPP}=\min \left(\mathrm{NPP}_{\mathrm{T}}, \mathrm{NPP}_{\mathrm{P}}\right),
$$

With

$$
\begin{aligned}
& \mathrm{NPP}_{\mathrm{T}}=3000 /\left(1+\mathrm{e}^{1.315-0.119 \mathrm{t}}\right) \\
& \mathrm{NPP}_{\mathrm{P}}=3000\left(1-\mathrm{e}^{-0.000664 \mathrm{p}}\right),
\end{aligned}
$$

where $t$ is the annual mean temperature $\left({ }^{\circ} \mathrm{C}\right)$, and $\mathrm{p}$ is annual precipitation $(\mathrm{mm})$.

HNPP, reflecting the impact of human activities on ecosystems, can be quantified as the difference between PNPP and actual NPP (see Formula (4)) [39]. Positive HNPP represents negative impacts of human activities; whereas negative HNPP indicates that 
human activities promote NPP. The relative contributions of climate variation and human activities on NPP can be identified by comparing the slope of NPP, PNPP and HNPP [39,40].

$$
\mathrm{HNPP}=\mathrm{PNPP}-\mathrm{NPP},
$$

\subsubsection{Changing Trend Analysis of FVC, NPP, PNPP, and HNPP}

Linear regression can simulate the changing trend of each pixel in space, and reflect the changing trend of the entire space (see Formula (5)). If the slope is positive, it reflects an increasing trend, otherwise, it indicates a decreasing trend. The larger the slope, the more obvious the changing trend. Linear regression analysis was used to detect the spatialtemporal variation of vegetation indexes (including NPP, FVC, PNPP, and HNPP) from 2011 to 2019 on pixel level.

$$
X_{\text {slope }}=\frac{\mathrm{n} \times \sum_{\mathrm{i}=1}^{\mathrm{n}}\left(\mathrm{i} \times \mathrm{X}_{\mathrm{i}}\right)-\left(\sum_{\mathrm{i}=1}^{\mathrm{n}} \mathrm{i}\right)\left(\sum_{\mathrm{i}=1}^{\mathrm{n}} \mathrm{X}_{\mathrm{i}}\right)}{\mathrm{n} \times \sum_{\mathrm{i}}^{\mathrm{n}} \mathrm{i}^{2}-\left(\sum_{\mathrm{i}=1}^{\mathrm{n}} \mathrm{i}\right)^{2}},
$$

where $\mathrm{X}$ are the indexes (NPP, FVC, PNPP, or HNPP); $\mathrm{n}$ is the total of monitoring years; and $i$ is the ith year.

\subsubsection{Variation Analysis of FVC, NPP, PNPP, and HNPP}

The coefficient of variation (CV) is used to measure the degree of variation of observations (see Formula (6)). In this study, the model is used to analyze the variation of VIs (NPP, FVC, PNPP, and HNPP) in the time series on pixel level. This reflects the discreteness and volatility of the data. Higher values of $\mathrm{CV}$ indicate a more discrete data distribution, higher volatility and drastic changes.

$$
\mathrm{CV}=\frac{\sigma}{\overline{\mathrm{x}} \prime}
$$

where $\sigma$ is standard deviation; $\bar{x}$ is the average value.

\subsubsection{Grassland Change Classification}

With a focus on the indexes that reflect grassland conditions from a qualitative aspect (FVC) and quantitative aspect (NPP), more analysis in respect to their changing trend $\left(\mathrm{X}_{\text {slope }}\right)$ and variation $(\mathrm{CV})$ over a time series is possible. Based on the analysis, we classified the grassland change trend in IMAR into four categories. If both NPP and FVC show increasing trends $\left(X_{\text {slope }}>0\right)$, pixels are classified as synthetic increase; if NPP or FVC show a decreasing trend $\left(\mathrm{X}_{\text {slope }}<0\right)$, pixels are classified as decreasing trend, using Slope $_{n f}$ to represent the synthetic slope of NPP (Slope ${ }_{\mathrm{NPP}}$ ) and FVC (Slope ${ }_{\mathrm{FVC}}$ ) for each pixel. With the study region as a reference, we get the mean value of $\mathrm{CV}$ of the whole region (i.e., 0.20, in this study). Relevant variation degree would be classified into fluctuating $(\mathrm{CV}>0.20)$ and persistent $(\mathrm{CV}<0.20)$ categories. To highlight the fluctuation factor and reveal the potential threats in advance, the maximum value of $C V$ for NPP and FVC in each pixel was compared $\left(\mathrm{CV}_{\mathrm{nf}}=\operatorname{Max}\left(\mathrm{CV}_{\mathrm{NPP}}, \mathrm{CV}_{\mathrm{FVC}}\right)\right)$. Based on the above, the four following categories can be derived (see Table 2): (1) fluctuating increasing trend (Slope $_{\mathrm{NPP}}>0$ and Slope $\mathrm{FVC}_{\mathrm{C}}>0 ; \mathrm{CV}_{\mathrm{nf}} \geq \mathrm{MeanCV}_{\mathrm{nf}}$ ); (2) fluctuating decreasing trend (Slope $_{\mathrm{NPP}}<0$ or Slope $\mathrm{FVC}<0 ; \mathrm{CV}_{\mathrm{nf}} \geq \mathrm{MeanCV}_{\mathrm{nf}}$ ); (3) persistent increasing trend (Slope $_{\mathrm{NPP}}>0$ and Slope $\mathrm{FVC}>0 ; \mathrm{CV}_{\mathrm{nf}}<\mathrm{MeanCV}_{\mathrm{nf}}$ ); (4) persistent decreasing trend (Slope $_{\mathrm{NPP}}<0$ or Slope $\mathrm{FVC}<0 ; \mathrm{CV}_{\mathrm{nf}}<\mathrm{MeanCV}_{\mathrm{nf}}$ ). 
Table 2. Classification of grassland change type from 2011 to 2019.

\begin{tabular}{|c|c|c|c|c|}
\hline \multirow{2}{*}{$\begin{array}{c}\text { Item } \\
\text { Slope }_{\mathrm{NPP}}\end{array}$} & \multicolumn{4}{|c|}{ Factor } \\
\hline & & & $>0$ & $<0$ \\
\hline Slope & & & $<0$ & $<0$ \\
\hline Slope $_{n f}$ & \multicolumn{2}{|c|}{$>0$} & \multicolumn{2}{|r|}{$<0$} \\
\hline $\begin{array}{l}\mathrm{CV}_{\mathrm{nf}} \\
\text { Zone }\end{array}$ & $\begin{array}{c}\geq \text { MeanCV }_{\mathrm{nf}} \\
\text { Fluctuating } \\
\text { increasing trend }\end{array}$ & $\begin{array}{c}<\mathrm{MeanCV}_{\mathrm{nf}} \\
\text { Persistent } \\
\text { increasing trend }\end{array}$ & $\begin{array}{c}\geq \text { MeanCV }_{\mathrm{nf}} \\
\text { Fluctuating } \\
\text { decreasing trend }\end{array}$ & $\begin{array}{c}<\mathrm{MeanCV}_{\mathrm{nf}} \\
\text { Persistent decreasing } \\
\text { trend }\end{array}$ \\
\hline
\end{tabular}

$\mathrm{CV}_{\mathrm{nf}}=\operatorname{Max}\left(\mathrm{CV}_{\mathrm{NPP}}, \mathrm{CV}_{\mathrm{FVC}}\right)$; MeanCV $\mathrm{nf}_{\mathrm{nf}}$ : the mean value of $\mathrm{CV}_{\mathrm{nf}}$, in this study, is 0.20 .

\subsubsection{Grassland Change Matrix in the Last Two Years}

Due to climate change and increase of extreme events, random and unpredictable factors are one of the major threats for pastoralists in grassland areas [41]. Therefore, it is essential to consider these factors to support sustainable grassland management strategies. In addition to the time series analyses in the above sections, we explored grassland change only within two adjacent years to reflect the random factor. Considering the yearly-based adjustment feature of SISGC, the latest years of 2018 and 2019 were set as an exploration. A spatial transfer matrix based on FVC and NPP results was designed.

\section{Results}

\subsection{Spatial-Temporal Change Characteristics of Grassland}

\subsubsection{Spatial Characteristics of Grassland}

The FVC in IMAR is increasing from west to east (see Figure 2 left). The highest grasslands coverage is in the range of $40 \%$ to $60 \%$, accounting for $24.83 \%$ of the total area. This area is mainly concentrated in the central part of IMAR, covering the western part of Hulunbuir and the central part of Xilin Gol. The region with less than $20 \%$ of grass vegetation covers $18.62 \%$ of IMAR and is concentrated in the west, including the western part of Xilin Gol and most area of Alxa, Bayan Nur, Bautou and Ulanqab.
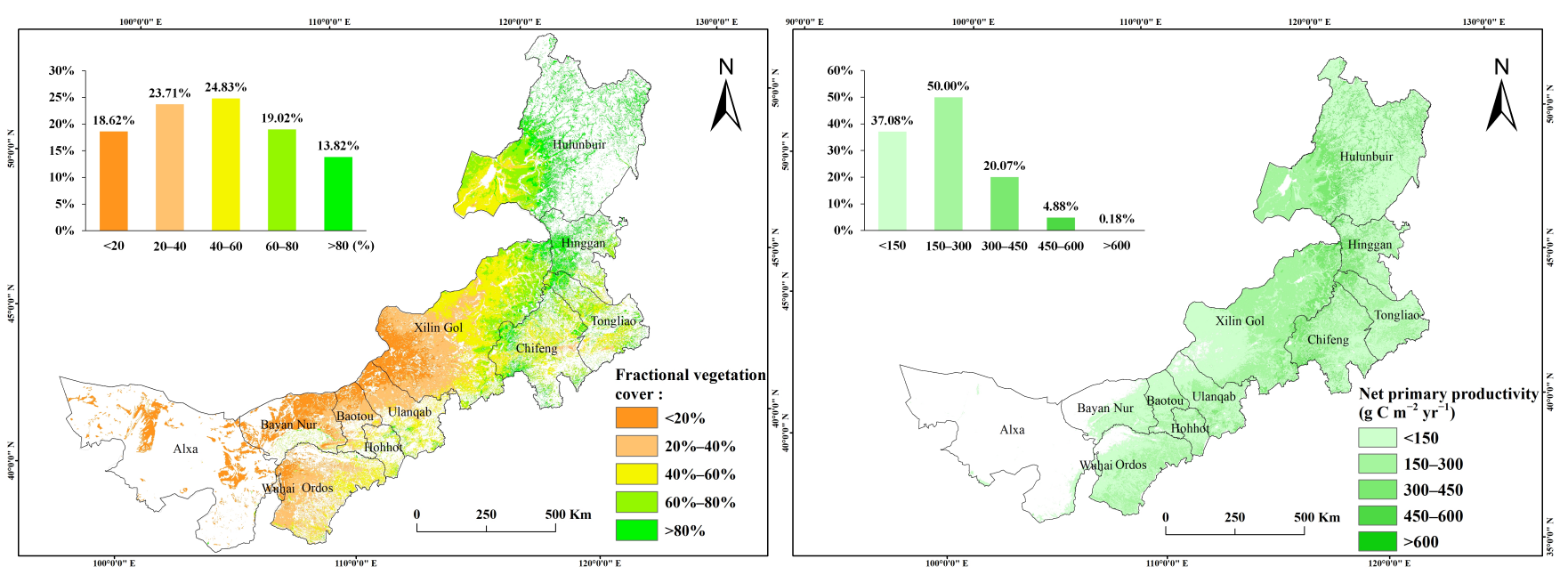

Figure 2. The spatial distribution of average NPP and FVC in the Inner Mongolia Autonomous Region (IMAR) from 2011 to 2019.

The average NPP of grasslands in IMAR shows an increasing, then decreasing trend from west to east (see Figure 2 right). The area with the highest NPP is concentrated to the west of Hulunbuir and Hinggan with mainly distributed meadow steppe and typical steppe. About $50.00 \%$ of grassland within the whole area has an average NPP in the range of $150 \mathrm{gCm}^{-2} \mathrm{yr}^{-1}$ to $300 \mathrm{gCm}^{-2} \mathrm{yr}^{-1}$. However, the grassland production under $150 \mathrm{gCm}^{-2} \mathrm{yr}^{-1}$ is the second-highest category covering $37.08 \%$ of grassland in IMAR. 


\subsubsection{Spatial-Temporal Change of Grassland from 2011 to 2019}

Both FVC and NPP in IMAR showed an increasing trend (see Table 3). The multi-year average FVC is 0.48 and the multi-year average NPP is $124.83 \mathrm{gCm}^{-2} \mathrm{yr}^{-1}$. The trends of FVC and NPP in IMAR are positive. More than half of the regions showed an increasing trend in FVC and NPP, with proportions of $52.71 \%$ and $50.43 \%$, respectively. The increasing trend of FVC is not apparent, with a mean slope value of 0.001 . However, NPP reflects an obviously relevant increasing trend (mean value is 10.45).

Table 3. Slope and CV of FVC, NPP, PNPP, HNPP of grassland in IMAR from 2011 to 2019.

\begin{tabular}{cccccccc}
\hline & \multirow{2}{*}{ Mean } & \multicolumn{4}{c}{ Slope } & \multicolumn{2}{c}{ CV } \\
\cline { 3 - 8 } & & + & - & Mean & STD & Mean & STD \\
\hline FVC & 0.48 & $52.71 \%$ & $46.53 \%$ & 0.001 & 0.009 & 0.22 & 0.18 \\
NPP & 124.83 & $50.43 \%$ & $39.63 \%$ & 10.45 & 35.72 & 0.14 & 0.06 \\
PNPP & 230.56 & $65.99 \%$ & $30.12 \%$ & 2.4 & 6.54 & 0.19 & 0.07 \\
HNPP & 166.94 & $63.32 \%$ & $23.04 \%$ & 2.57 & 6.21 & 0.26 & 0.43 \\
\hline
\end{tabular}

Due to better rain conditions, $65.99 \%$ PNPP of grassland shows a relevant insignificant increasing trend. The multi-year average of HNPP is $166.94 \mathrm{gCm}^{-2} \mathrm{yr}^{-1}$, the positive value of HNPP reflecting a negative impact of human activities. Furthermore, HNPP has increased in $63.32 \%$ of grassland areas. Considering the fact that the actual NPP shows an increasing trend in the whole region of IMAR, the impact of multi-factors, including the positive effects of precipitation and grassland restoration, as well as disturbing effects from human activities, should be considered when assessing local grassland use conditions. In addition, both FVC and NPP of grassland show fluctuations from 2011 to 2019. Especially for FVC, the average CV for annual FVC is 0.22 . Fluctuating FVC reflects the unpredictability of grassland condition and challenges sustainable grassland management.

\subsection{Grassland Cover Change Trend Analysis}

3.2.1. Grassland Cover Change Trend Classification from 2011 to 2019

Combining FVC with NPP, the northern part of IMAR reflected an obviously decreasing trend, while the western part of IMAR fluctuates more strongly (see Figure 3). Around $33.69 \%$ of grasslands in IMAR are above the average coefficient of variation for the whole area and also show a decreasing trend. These areas are mainly located in the meadow steppe area in the west of Hulunbuir, Hinggan and east of Xilin Gol. Under good climatic conditions, the persistent decreasing trend reveals a constant human pressure on these meadow and typical steppe areas. With a lower precipitation rate, the western area is more sensitive to climate factors and reflects both increasing $(19.21 \%)$ and decreasing trends $(25.69 \%)$. Areas with an increasing trend are concentrated in the west and southeast area, covering the main part of Ordos, Hohhot, Bayan Nur, Baotou and Ulanqab. With mainly semi-desert grassland in these areas, the fluctuating increasing trend of $19.21 \%$ and persistent increasing trend of $21.42 \%$ reflects an overall improvement of grassland condition both in vegetation coverage and production.

\subsubsection{Grassland Change Matrix from 2018 to 2019}

Compared to 2018, only $15.03 \%$ of grassland shows an increase in both NPP and FVC in 2019 , while $41.60 \%$ of the grassland area shows a decrease in NPP and FVC. The decreasing areas are mainly distributed in typical steppe zones including areas north of Xilin Gol, and west of Hulunbair and Ordos (see Figure 4). According to the meteorological data, annual average precipitation in IMAR was $346 \mathrm{~mm}$ in 2019, which is comparable to the precipitation of $369 \mathrm{~mm}$ in 2018. Nevertheless, there is high spatial variability throughout the year. In Xilin Gol league, where the majority of grasslands are typical grasslands, the precipitation was $261 \mathrm{~mm}$ during the grassland growing season in 2019, which was $89 \mathrm{~mm}$ less than the previous year (percentage of precipitation anomaly, 34\%). The average 
temperature was $14.5^{\circ} \mathrm{C}, 1.2{ }^{\circ} \mathrm{C}$ higher than in the previous years. Less precipitation and higher temperatures in mid-season are the main factors affecting the formation and growth of forage production in Xilin Gol League in 2019 [42]. This phenomenon reveals the fact that areas with better precipitation conditions and grass production show a more obvious amplitude of vegetation change. On the other hand, the unpredictable annual meteorological conditions are a challenge for a precise livestock-forge balance policy, as well as effective implementation of SISGC. These projects need to set rules for the size of households' livestock according to the grassland condition of the exact current year.

\subsection{Climate and Human Activities Impact}

Annual mean NPP, PNPP and HNPP show an overall increasing trend (see Figure 5). PNPP, affected by meteorological factors, shows an obvious trend with a slope of 2.4432, reflecting a positive impact of precipitation and temperature for the grassland system. However, HNPP shows a higher increasing trend (slope $=2.658$ ). According to the statistical data, the number of livestock in IMAR increased from 68.06 million in 2011 to 71.92 million in 2019 [43]. Although the actual NPP in the past decade shows a gradually increasing trend (slope $=0.3115$ ), pressure from human activities also exists. A positive aspect is that livestock numbers have decreased from 73.52 million in 2016 to 71.92 million in 2019, when the second round of SISGC was launched. The actual NPP increased from $117.43 \mathrm{gCm}^{-2} \mathrm{yr}^{-1}$ in 2016 to $130.38 \mathrm{gCm}^{-2} \mathrm{yr}^{-1}$ in 2019. This positive fact reveals the potential for an improvement of grassland conditions through appropriate grassland management measures.

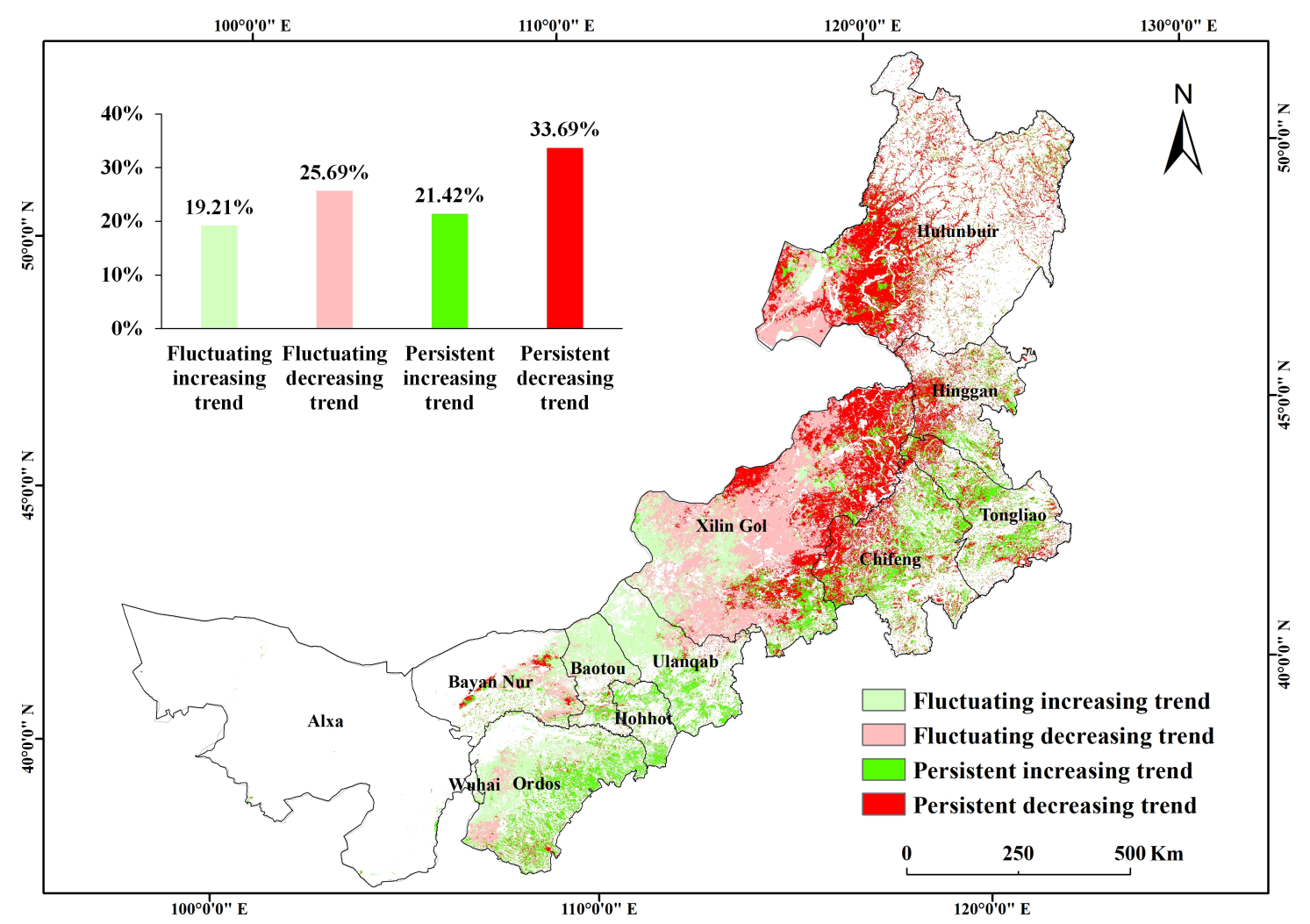

Figure 3. Grassland change trend classification in IMAR from 2011 to 2019 (On pixel level: Fluctuating increasing trend $\left(\right.$ Slope $_{\mathrm{NPP}}>0$ and Slope $\mathrm{FVC}>0 ; \mathrm{CV}_{\mathrm{nf}} \geq \mathrm{MeanCV}_{\mathrm{nf}}$ ); Fluctuating decreasing trend (Slope $\mathrm{NPP}_{\mathrm{NP}}<0$ or Slope $\mathrm{FVC}<0$; $\mathrm{CV}_{\mathrm{nf}} \geq$ MeanCV $_{\mathrm{nf}}$ ); Persistent increasing trend (Slope $\mathrm{NPP}>0$ and Slope $\mathrm{FVC}>0 ; \mathrm{CV}_{\mathrm{nf}}<\mathrm{MeanCV}_{\mathrm{nf}}$ ); Persistent decreasing trend $\left(\right.$ Slope $_{\mathrm{NPP}}<0$ or Slope $\mathrm{FVC}_{2}<0 ; \mathrm{CV}_{\mathrm{nf}}<\mathrm{MeanCV}_{\mathrm{nf}}$ ); Slope $\mathrm{NPP}_{\mathrm{N}}$ : slope of NPP; Slope $\mathrm{FVC}$ : slope of FVC; $\mathrm{CV}_{\mathrm{nf}}$ : Maximum one in CV of NPP and CV of FVC; MeanCV ${ }_{n f}$ : mean value of $\mathrm{CV}_{\mathrm{nf}}$ ). 


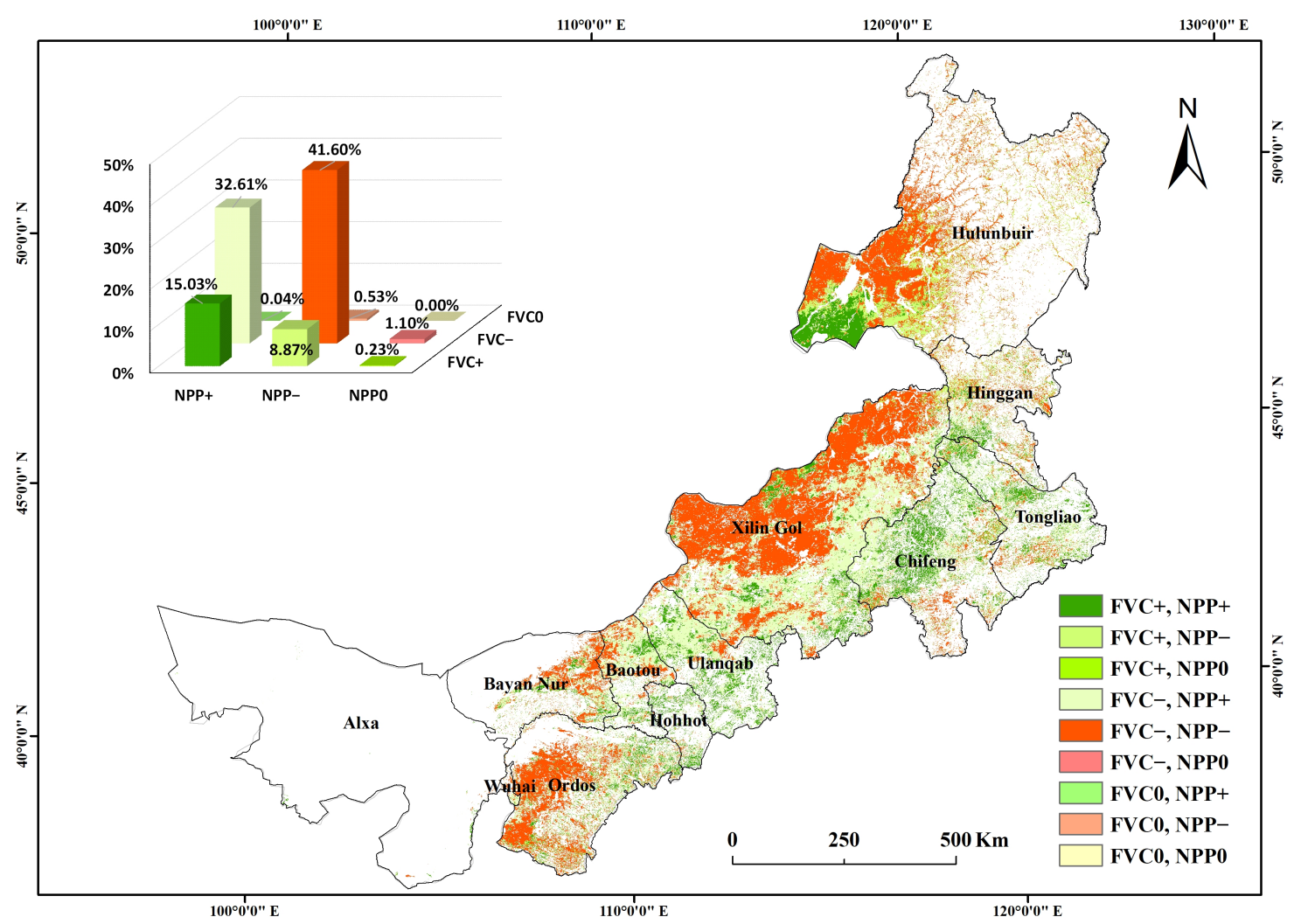

Figure 4. Spatial change matrix of NPP and FVC from 2018 to 2019 (Note: "+" means increased;"-" means decreased; “0” means no change.).

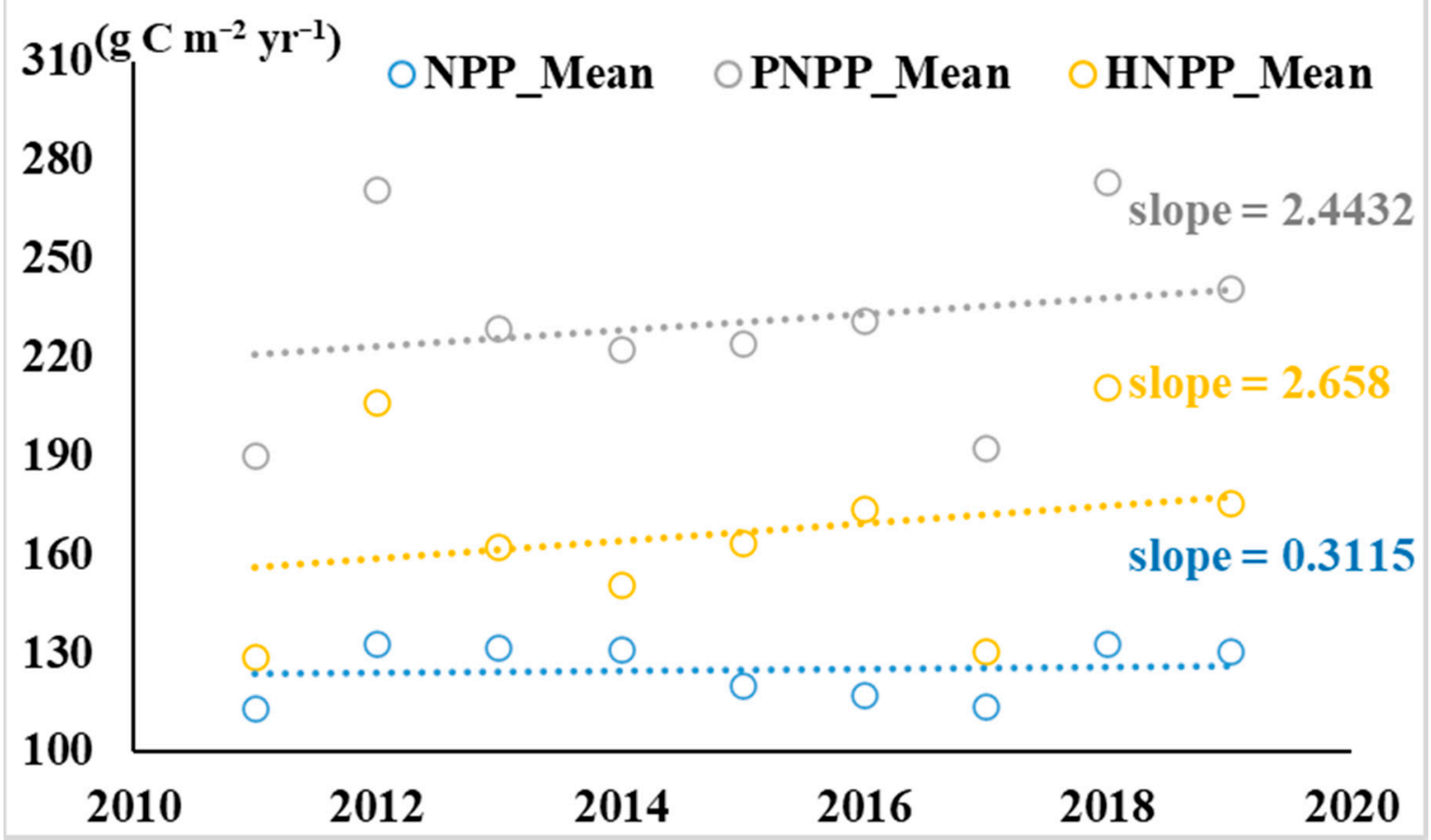

Figure 5. Change trend of NPP, PNPP and HNPP from 2011 to 2019. 


\section{Discussion and Conclusions}

Through the combination of MODIS data with up to date meteorological data, and employing the indicators of FVC and NPP in both vegetation's qualitative and quantitative aspects, we analyzed the grassland development in IMAR since 2011, when the comprehensive grassland conservation program (SISGC) was launched.

\subsection{The Positive Effect of SISGC, Especially in the Western Semi-Desert Grassland Area}

Many researchers have tried to reveal and explore the change of grassland development, especially the degradation condition after the implementation of environmental conservation projects, such as the improvement of height, coverage, and biomass of natural grassland. However, results are often spatially and temporally inconsistent. Some studies showed that grassland condition has recovered to some extent in the past decades [24], while others claim that overall grassland condition has continued to deteriorate and grassland degradation is still the major ecological issue [25]. However, recent researches revealed that the year 2011 can be seen as a turning point for grassland dynamic trends in IMAR. By empirically analyzing the NDVI developing trend based on data of 52 counties across a 15-year timespan, results showed that there was a deteriorating trend between 2001 and 2010, followed by an improving trend since 2011 [44]. Studies of vegetation growth dynamics based on EVI since 2000 also reflected an obvious turning point in 2011 (Figure 3 in the reference research) showing a significant standard deviation in 2012 [45]. NDVI studies based on datasets of NASA's Earth Science Data Systems Programs from 2001 to 2014 also showed a visible increasing trend since 2011 (Figure 2 in the reference research) [24].

Based on these studies, the SISGC implementation in 2011 seems to have positively contributed to local grassland conservation in IMAR. The continuous effects in the past ten years and the potential yearly adjustment for the SISGC seem more practically essential. We chose to use FVC and NPP as two main indicators for detection of grassland change in IMAR, using FVC to visualize grassland quantity and NPP to assess product quality. These two aspects are in line with the national standards of Peoples' Republic of China "parameters for degradation, sandification and salification of rangelands (GB19377-2003)" [46]. The indicators proved to be effective for appropriate grassland degradation monitoring in IMAR [17]. Our study results reflected the positive effects of grassland recovery since 2011. Both FVC and NPP showed an increasing trend (Section 3.1.2). Su's research based on field survey data in IMAR also indicated that the aboveground NPP of different grassland types increased significantly between 2011 to 2013, in line with the progress of the national ecological program [47].

Besides, our study shows that the positive effect since 2011 is spatially unbalanced. The grassland change trend classification (Figure 3) shows that most green pixels (increase) are concentrated in the western part of IMAR's grassland area, while most of the red pixels (decrease) are distributed in the upper eastern part. The grassland types in IMAR are desert steppe, typical steppe, and meadow steppe [25] following a precipitation gradient from west to east. Thus, the increasing trend or the positive effect is more obvious in the western part with desert steppe than in the eastern part with typical and meadow steppe. For example, in Baotou, where semi-desert grasslands are characteristic, the combined NPP and FVC classification system indicates that $86.03 \%$ of grassland shows a fluctuating or a persistent increasing trend. However, in Hulunbuir, characterized by meadow and typical steppe, only $16.99 \%$ of grassland shows an increasing trend. The possible reason might be that semi-desert grassland with poor ecological conditions has a higher potential for improvement. However, the significantly lower increasing trend in typical and meadow grassland possibly reflects that these areas receive less attention.

\subsection{Potential Threats and Possible Reasons: Social and Natural Effects on Grassland Change}

From 2011 to 2019, the annual average precipitation in IMAR increased from $110.39 \mathrm{~mm}$ to $120.00 \mathrm{~mm}$; The annual average temperature also increased from $3.78{ }^{\circ} \mathrm{C}$ to $5.02{ }^{\circ} \mathrm{C}$ (See supplement file, Table S1). These positive climatic factors for grassland production 
result in an increase of PNPP (See Formula (3), Section 2.3.2). However, HNPP also shows an increasing trend (Section 3.1.2), implicating the intensity of human activities. Spatially, the annual average precipitation decreases from east to west of IMAR (See supplement file, Figure S1). The analysis of spatial-temporal precipitation change, based on available data from 2010 to 2015 in a $1 \mathrm{~km}$ spatial resolution (See supplement file, Figure S2), shows an increasing trend of precipitation in the eastern part, where typical and meadow steppe dominated. Improving natural climatic conditions will most probably improve grassland production in these areas. However, the grassland classification results show a decreasing trend in most of these areas (Figure 3). The contrasting results are alarming for the implementation of the grassland conservation program. The additional increase of PNPP and NPP in the whole region might cover up the negative effects, especially in areas under better precipitation conditions.

Considering SISGC implementation, Hu's field survey in 2015 revealed that SISGC had limited impact on herders' livestock production and grazing management, especially for herders in good grassland regions [48]. The compensation is much lower compared to possible market benefits and seems to be less attractive, although the subsidy and reward from central government on SISGC in IMAR are approximately 3.2 billion USD for the first round (2011-2015) [48]. Statistical data shows that stocking livestock in IMAR increased from 68.06 million to 91.92 million between 2011 and 2019 [43]. A household survey research also revealed that the overall stocking rate marginally increased significantly [49]. Herders were found to be more sensitive to market signals rather than the subsidy [48]. Local government encountered increasing supervision costs when the producer price of live sheep soared, which prompted local herders to gain more economic benefits by increasing illegal grazing [24]. The difficult tasks for local government may also lead to the malfunction of SISGC implementation to some extent. Some researchers have pointed out that the determination of a maximum stocking rate and various grazing bans have a less feasible effect under the spatial heterogeneity of grasslands and climate variability [50], and the effectiveness of conservation strategies in arid and semi-arid areas need to be discussed thoroughly [51]. Integrated management considering climate conditions, geographical characteristics and socioeconomic factors is prospected to be beneficial for regional grassland conservation [52].

The grassland ecosystems are ecologically vulnerable and sensitive to climate change [53]. Vegetation phenology in temperate grasslands is highly sensitive [54]. Gong et al. observed that the length of the growing season in grassland regions of IMAR has increased by 10.86 days from 2002 to 2014 [21]. Ren et al. also revealed that during 2000 to 2015, the start of the growing season in typical steppe and desert steppe has significantly advanced by 2.2 days and 10.6 days, and the end of the growing season in desert steppe has also significantly advanced by 6.8 days [54]. Combining the phenology changing results under the background of unavoidable global climate change could help to guide grazing systems and to develop more efficient policy frameworks for grassland protection.

\subsection{The Importance of a Meteorological Prediction System for Local Stakeholders}

The difference between 2018 and 2019 (Section 3.2.2) reveals the impact of unpredictable meteorological conditions. Although conservation programs and human efforts can make a positive difference in the grassland region, the sensitivity of vulnerable grassland systems to environmental factors still acts as the main driver. This also sets obstacles for a successful implementation of grassland conservation programs, balancing the capacity of grassland and livestock on a yearly basis. Under these circumstances, an earlier and up-to-date grassland growing prediction system is of great importance, not only for the equitable implementation of conservation projects but also for efficient grassland use strategies of herders. Local government could develop improved planning for implementation of grazing bans or forage-livestock balancing measures in the region; herders could decide whether natural grassland needs to be reserved or could rationally be used during a predictable good production year. A similar project has already been employed in 
Mongolia, where natural hazards are the main issues in grassland systems [55], through the use of near real-time satellite-based climate data, computer simulation and modelling. Mongolia's livestock early warning system, accessible to all people, monitors and forecasts livestock forage conditions to help pastoralists and decision makers make timely decisions while facing natural hazards. This system can be a good reference for IMAR and other pastoral areas in the world in need of balanced grassland management.

Some issues still need to be addressed beyond this research. Firstly, in the binary pixel model for calculation of FVC, the impact of soils on vegetation signatures is an important factor which often causes errors. The parameters of $\mathrm{NDVI}_{\mathrm{S}}$ and $\mathrm{NDVI}_{\mathrm{V}}$ are always under discussion and the selection principles vary throughout the research, especially concerning the determination of $\mathrm{NDVI}_{\mathrm{s}}$. Basically, the $\mathrm{NDVI}_{\mathrm{S}}$ vary from -0.1 to 0.2 [56]. The estimation study of FVC in Northeast China pointed out that $\mathrm{NDVI}_{\mathrm{s}}$ ranges between 0.07 and 0.22 [37]. Research on FVC estimation in arid and semi-arid environments recommended $\mathrm{NDVI}_{\mathrm{s}}$ and $\mathrm{NDVI}_{\mathrm{V}}$ in grassland are 0.045 and 0.593 , respectively [57]. Estimation research of FVC in IMAR by MODIS data in 2013 obtained the result that $\mathrm{NDVI}_{\mathrm{s}}$ and $\mathrm{NDVI}_{\mathrm{V}}$ in grassland are 0.118 and 0.806 , while with in situ measurement the results are 0.203 and 0.891 [34]. In this research, the mean value of $\mathrm{NDVI}_{\mathrm{S}}$ and $\mathrm{NDVI}_{\mathrm{V}}$ from 2011 to 2019 are $0.07(\mathrm{CV}=0.0 \%)$ and $0.89(\mathrm{CV}=0.7 \%)$. The value of $\mathrm{NDVI}_{\mathrm{S}}$ shows in the normal ranges as mentioned above, but is lower than values obtained through in situ data in 2013. The value of $\mathrm{NDVI}_{\mathrm{V}}$ is accordance with the MODIS and in situ research result in IMAR [34]. Secondly, although the study has qualitatively and quantitatively analyzed the change of grassland based on FVC and NPP indicators, grassland species succession during the process of grassland degradation may also contain the increase of mixed shrub types, which will also lead to an increase in both FVC and NPP. As such it will be important to develop a method to differentiate between shrubs and grassland. With the development of LiDAR, hyperspectral data and unmanned aerial vehicles, attempts are arising in discriminate specific grassland species [58]. Although limited to regional and short-term studies due to limited data access and high-cost data, this discrimination process should be incorporated into future research to provide more precise grassland change results and reliable support for local decision making. Besides, livestock always act as the basic conjunction between human society and environment. Individual animal health and performance change (i.e., body condition, reproduction) need more attention for a thorough understanding of the effectiveness, impaction and sustainability of grassland conservation programs.

Supplementary Materials: The following are available online at https:/ / www.mdpi.com/2073-4 45X/10/1/38/s1, Figure S1: Precipitation spatial distribution of IMAR in 2015, Figure S2: Precipitation change in IMAR from 2010 to 2015, Table S1: Changing of annual average temperature and precipitation in IMAR.

Author Contributions: Conceptualization, M.K. and Z.X.; methodology and analysis, Z.X.; writingoriginal draft preparation, Z.X.; writing-review and editing, D.W., M.K. and Z.X.; All authors have read and agreed to the published version of the manuscript.

Funding: This research received no external funding.

Institutional Review Board Statement: Not applicable.

Informed Consent Statement: Not applicable.

Data Availability Statement: The data presented in this study are available on request from the corresponding author.

Acknowledgments: Thanks to the anonymous reviewers for providing us with constructive comments and Prof Jiquan Chen for critical comments on the early version of the manuscript. We are grateful for the open access publishing support from Göttingen State and University Library (SUB), University of Göttingen. Z.X. acknowledges the scholarship support from Sino-German (CSC-DAAD) Program, 2019.

Conflicts of Interest: The authors declare no conflict of interest. 


\section{References}

1. Veldman, J.W.; Buisson, E.; Durigan, G.; Fernandes, G.W.; Le Stradic, S.; Mahy, G.; Negreiros, D.; Overbeck, G.E.; Veldman, R.G.; Zaloumis, N.P.; et al. Toward an old-growth concept for grasslands, savannas, and woodlands. Front. Ecol. Environ. 2015, 13, 154-162. [CrossRef]

2. Vova, O.; Kappas, M.; Emam, A.R. Comparison of Satellite Soil Moisture Products in Mongolia and Their Relation to Grassland Condition. Land 2019, 8, 142. [CrossRef]

3. de Faccio Carvalho, P.C.; Batello, C. Access to land, livestock production and ecosystem conservation in the Brazilian Campos biome: The natural grasslands dilemma. Livest. Sci. 2009, 120, 158-162. [CrossRef]

4. Suttie, J.; Reynolds, S.; Batello, C. Grasslands of the World; Food and Agriculture Organization of the United Nations: Rome, Italy, 2005.

5. Liu, Y.; Liu, Q.; Sun, X.; Zhang, X.; Kang, S.; Ding, Y.; Zhang, Q.; Niu, J. The applicability of the species pool hypothesis to community diversity in the Inner Mongolia grassland along a mean annual precipitation gradient. Acta Ecol. Sin. 2016, 36, 442-447. [CrossRef]

6. Akiyama, T.; Kawamura, K. Grassland degradation in China: Methods of monitoring, management and restoration. Grassl. Sci. 2007, 53, 1-17. [CrossRef]

7. Li, A.; Wu, J.; Huang, J. Distinguishing between human-induced and climate-driven vegetation changes: A critical application of RESTREND in inner Mongolia. Landsc. Ecol. 2012, 27, 969-982. [CrossRef]

8. Jiang, B.; Bai, Y.; Wong, C.P.; Xu, X.; Alatalo, J.M. China's ecological civilization program-Implementing ecological redline policy. Land Use Policy 2019, 81, 111-114. [CrossRef]

9. UNEP. Green is Gold: The Strategy and Actions of China's Ecological Civilization; UNEP: Nairobi, Kenya, 2016.

10. Fargione, J.E.; Cooper, T.R.; Flaspohler, D.J.; Hill, J.; Lehman, C.; Tilman, D.; McCoy, T.; McLeod, S.; Nelson, E.J.; Oberhauser, K.S. Bioenergy and Wildlife: Threats and Opportunities for Grassland Conservation. BioScience 2009, 59, 767-777. [CrossRef]

11. Robinson, B.E.; Li, P.; Hou, X.Y. Institutional change in social-ecological systems: The evolution of grassland management in Inner Mongolia. Glob. Environ. Chang. Hum. Policy Dimens. 2017, 47, 64-75. [CrossRef]

12. Zhang, P.; Shao, G.; Zhao, G.; Le Master, D.C.; Parker, G.R.; Dunning, J.B.; Li, Q. China's Forest Policy for the 21st Century. Science 2000, 288, 2135. [CrossRef]

13. Mansour, K.; Mutanga, O.; Everson, T. Remote sensing based indicators of vegetation species for assessing rangeland degradation: Opportunities and challenges. Afr. J. Agric. Res. 2012, 7, 3261-3270. [CrossRef]

14. Gu, Q.; Zheng, H.; Yao, L.; Wang, M.; Ma, M.; Wang, X.; Tang, X. Performance of the Remotely-Derived Products in Monitoring Gross Primary Production across Arid and Semi-Arid Ecosystems in Northwest China. Land 2020, 9, 288. [CrossRef]

15. Zhumanova, M.; Mönnig, C.; Hergarten, C.; Darr, D.; Wrage-Mönnig, N. Assessment of vegetation degradation in mountainous pastures of the Western Tien-Shan, Kyrgyzstan, using eMODIS NDVI. Ecol. Indic. 2018, 95, 527-543. [CrossRef]

16. Zhang, G.; Biradar, C.; Xiao, X.; Dong, J.; Zhou, Y.; Qin, Y.; Zhang, Y.; Liu, F.; Ding, M.; Thomas, R. Exacerbated grassland degradation and desertification in Central Asia during 2000-2014. Ecol. Appl. 2017, 28. [CrossRef]

17. Zhou, W.; Li, J.; Yue, T. Grassland Degradation Remote Sensing Monitoring and Driving Factors Quantitative Assessment in China from 1982 to 2010. Ecol. Indic. 2020, 83, 303-313. [CrossRef]

18. Han, D.; Wang, G.; Xue, B.L.; Liu, T.; Aa, Y.; Xu, X. Evaluation of semiarid grassland degradation in North China from multiple perspectives. Ecol. Eng. 2018, 112, 41-50. [CrossRef]

19. Cao, J.; Adamowski, J.; Deo, R.; Xu, X.; Gong, Y. Grassland Degradation on the Qinghai-Tibetan Plateau: Reevaluation of Causative Factors. Rangel. Ecol. Manag. 2019. [CrossRef]

20. Tong, S.; Zhang, J.; Ha, S.; Lai, Q.; Ma, Q. Dynamics of Fractional Vegetation Coverage and Its Relationship with Climate and Human Activities in Inner Mongolia, China. Remote Sens. 2016, 8, 776. [CrossRef]

21. Gong, Z.; Kawamura, K.; Ishikawa, N.; Goto, M.; Wulan, T.; Alateng, D.; Yin, T.; Ito, Y. MODIS normalized difference vegetation index (NDVI) and vegetation phenology dynamics in the Inner Mongolia grassland. Solid Earth 2015, 6, 1185-1194. [CrossRef]

22. Guo, L.; Wu, S.; Zhao, D.; Yin, Y.; Leng, G.; Zhang, Q. NDVI-Based Vegetation Change in Inner Mongolia from 1982 to 2006 and Its Relationship to Climate at the Biome Scale. Adv. Meteorol. 2014, 2014, 692068. [CrossRef]

23. Wu, J.; Zhang, Q.; Li, A.; Liang, C. Historical landscape dynamics of Inner Mongolia: Patterns, drivers, and impacts. Landsc. Ecol. 2015, 30, 1579-1598. [CrossRef]

24. Liu, M.; Dries, L.; Heijman, W.; Huang, J.; Zhu, X.; Hu, Y.; Chen, H. The Impact of Ecological Construction Programs on Grassland Conservation in Inner Mongolia, China. Land Degrad. Dev. 2018, 29, 326-336. [CrossRef]

25. Hu, Y.; Nacun, B. An Analysis of Land-Use Change and Grassland Degradation from a Policy Perspective in Inner Mongolia, China, 1990-2015. Sustainability 2018, 10, 4048. [CrossRef]

26. Department of Agriculture and Animal Husbandry of Inner Mongolia Autonomous Region. Grassland Protection and Construction Planning in the 13th Five-Year Period of Inner Mongolia; Department of Agriculture and Animal Husbandry of Inner Mongolia Autonomous Region: Inner Mongolia, China, 2016.

27. Feng, Z.; John, R.; Zhou, G.; Shao, C.; Chen, J. Estimating Canopy Characteristics of Inner Mongolia's Grasslands from Field Spectrometry. Remote Sens. 2014, 6, 2239-2254. [CrossRef]

28. Liu, J.; Kuang, W.; Zhang, Z.; Xu, X.; Qin, Y.; Ning, J.; Zhou, W.; Zhang, S.; Li, R.; Yan, C.; et al. Spatiotemporal characteristics, patterns, and causes of land-use changes in China since the late 1980s. J. Geogr. Sci. 2014, 24, 195-210. [CrossRef] 
29. Statistics Bureau of Inner Mongolia Autonomous Region. 2019 Inner Mongolia Autonomous Region National Economic and Social Development Statistical Bulletin. 2020. Available online: http://www.nmg.gov.cn/zwgk/bmmsxxgk/zzqzsjg/tjj/fdzdgknr/20 2012/t20201208_331587.html (accessed on 4 January 2021).

30. Didan, K.; MOD13A1 MODIS/Terra Vegetation Indices 16-Day L3 Global 500m SIN Grid V006, NASA EOSDIS Land Processes DAAC, Editor. 2015, NASA Eosdis Land Processes DAAC. Available online: https://lpdaac.usgs.gov/ (accessed on 6 April 2020).

31. Zhou, W.; Yang, H.; Zhou, L.; Chen, Y.; Huang, L.; Ju, W. Dynamics of grassland carbon sequestration and its coupling relation with hydrothermal factor of Inner Mongolia. Ecol. Indic. 2018, 95, 1-11. [CrossRef]

32. Gutman, G.; Ignatov, A. The derivation of the green vegetation fraction from NOAA/AVHRR data for use in numerical weather prediction models. Int. J. Remote Sens. 1998, 19, 1533-1543. [CrossRef]

33. Wu, D.; Wu, H.; Zhao, X.; Zhou, T.; Tang, B.; Zhao, W.; Jia, K. Evaluation of Spatiotemporal Variations of Global Fractional Vegetation Cover Based on GIMMS NDVI Data from 1982 to 2011. Remote Sens. 2014, 6, 4217-4239. [CrossRef]

34. Li, F.; Chen, W.; Zeng, Y.; Zhao, Q.; Wu, B. Improving Estimates of Grassland Fractional Vegetation Cover Based on a Pixel Dichotomy Model: A Case Study in Inner Mongolia, China. Remote Sens. 2014, 6, 4705-4722. [CrossRef]

35. Tang, L.; He, M.Z.; Xu, H.; Jia, P.C. Validation of vegetation coverage and NDVI based on UAV remote sensing method and its response to hydrothermal gradient. Chin. J. Appl. Ecol. 2020, 31, 35-44. [CrossRef]

36. Ma, L.; Cui, X.; Feng, Q.S.; Liang, T.G. Dynamic changes of grassland vegetation coverage from 2001 to 2011 in Gannan Prefecture. Acta Prataculturae Sin. 2014, 23, 1-9.

37. Ding, Y.; Zheng, X.; Zhao, K.; Xin, X.; Liu, H. Quantifying the Impact of NDVIsoil Determination Methods and NDVIsoil Variability on the Estimation of Fractional Vegetation Cover in Northeast China. Remote Sens. 2016, 8, 29. [CrossRef]

38. Lieth, H. Modeling the Primary Productivity of the World. In Primary Productivity of the Biosphere; Lieth, H., Whittaker, R.H., Eds.; Springer: Berlin/Heidelberg, Germany, 1975; pp. 237-263.

39. Liu, Y.; Zhang, Z.; Tong, L.; Khalifa, M.; Wang, Q.; Gang, C.; Wang, Z.; Li, J.; Sun, Z. Assessing the effects of climate variation and human activities on grassland degradation and restoration across the globe. Ecol. Indic. 2019, 106, 105504. [CrossRef]

40. Ugbaje, S.U.; Odeh, I.O.A.; Bishop, T.F.A.; Li, J. Assessing the spatio-temporal variability of vegetation productivity in Africa: Quantifying the relative roles of climate variability and human activities. Int. J. Digit. Earth 2017, 10, 879-900. [CrossRef]

41. John, R.; Chen, J.; Ou-Yang, Z.-T.; Xiao, J.; Becker, R.; Samanta, A.; Ganguly, S.; Yuan, W.; Batkhishig, O. Vegetation response to extreme climate events on the Mongolian Plateau from 2000 to 2010. Environ. Res. Lett. 2013, 8, 035033. [CrossRef]

42. Xilin Gol League Meteorological Bureau. Analysis Report of Nutrient Components of Natural Pastures in Xilin Gol League in 2019; Xilin Gol League Meteorological Bureau: Inner Mongolia, China, 2019.

43. Statistics bureau of Inner Mongolia Autonomous Region. Inner Mongolia Statistical Yearbook; China Statistics Press: Beijing, China; pp. 2011-2019.

44. Liu, M.; Dries, L.; Huang, J.; Min, S.; Tang, J. The impacts of the eco-environmental policy on grassland degradation and livestock production in Inner Mongolia, China: An empirical analysis based on the simultaneous equation model. Land Use Policy 2019, 88,104167 . [CrossRef]

45. He, D.; Huang, X.; Tian, Q.; Zhang, Z. Changes in Vegetation Growth Dynamics and Relations with Climate in Inner Mongolia under More Strict Multiple Pre-Processing (2000-2018). Sustainability 2020, 12, 2534. [CrossRef]

46. Ministry of Agriculture of the People's Republic of China, Parameters for Degradation, Sandification And salification of RANGELANDS 2003: Beijing. Available online: http:/ / www.eshian.com/standards/11780.html (accessed on 4 January 2021).

47. Su, R.; Yu, T.; Dayananda, B.; Bu, R.; Fan, Q. Impact of climate change on primary production of Inner Mongolian grasslands. Glob. Ecol. Conserv. 2020, 22, e00928. [CrossRef]

48. Hu, Y.; Huang, J.; Hou, L. Impacts of the Grassland Ecological Compensation Policy on Household Livestock Production in China: An Empirical Study in Inner Mongolia. Ecol. Econ. 2019, 161, 248-256. [CrossRef]

49. Yin, Y.; Hou, Y.; Langford, C.; Bai, H.; Hou, X. Herder stocking rate and household income under the Grassland Ecological Protection Award Policy in northern China. Land Use Policy 2019, 82, 120-129. [CrossRef]

50. Li, W.; Huntsinger, L. China's Grassland Contract Policy and its Impacts on Herder Ability to Benefit inInner Mongolia: Tragic Feedbacks. Ecol. Soc. 2011, 16, 1. [CrossRef]

51. Higgins, S.I.; Kantelhardt, J.; Scheiter, S.; Boerner, J. Sustainable management of extensively managed savanna rangelands. Ecol. Econ. 2007, 62, 102-114. [CrossRef]

52. Wang, Z.; Deng, X.; Song, W.; Li, Z.; Chen, J. What is the main cause of grassland degradation? A case study of grassland ecosystem service in the middle-south Inner Mongolia. CATENA 2017, 150, 100-107. [CrossRef]

53. Zhao, H.; Jia, G.; Wang, H.; Zhang, A.; Xu, X. Seasonal and interannual variations in carbon fluxes in East Asia semi-arid grasslands. Sci. Total Environ. 2019, 668, 1128-1138. [CrossRef]

54. Ren, S.; Yi, S.; Peichl, M.; Wang, X. Diverse Responses of Vegetation Phenology to Climate Change in Different Grasslands in Inner Mongolia during 2000-2016. Remote Sens. 2018, 10, 17. [CrossRef]

55. Mongolia Livestock Early Warning System. Mongolia Livestock Early Warning System. 2015 [cited 2020 2020-07-21]. Available online: http:/ / www.mongolialews.net/index.php/about/ (accessed on 29 June 2020).

56. Carlson, T.N.; Ripley, D.A. On the relation between NDVI, fractional vegetation cover, and leaf area index. Remote Sens. Environ. 1997, 62, 241-252. [CrossRef] 
57. Zhang, X.; Liao, C.; Li, J.; Sun, Q. Fractional vegetation cover estimation in arid and semi-arid environments using HJ-1 satellite hyperspectral data. IJAEO 2013, 21, 506-512. [CrossRef]

58. Fisher, R.J.; Sawa, B.; Prieto, B. A novel technique using LiDAR to identify native-dominated and tame-dominated grasslands in Canada. Remote Sens. Environ. 2018, 218, 201-206. [CrossRef] 